Check for updates

Cite this: RSC Adv., 2018, 8, 39444

Received 27th October 2018 Accepted 22nd November 2018

DOI: $10.1039 / \mathrm{c} 8 \mathrm{ra08903e}$

rsc.li/rsc-advances

\section{Exchange dynamics between amphiphilic block copolymers and lipidic membranes through hydrophobic pyrene probe transfer $\dagger$}

\author{
Lourdes Mónica Bravo-Anaya, (D)*abc Gabriel Landazuri Gómez, ${ }^{\mathrm{C}}$ Edgar Figueroa- \\ Ochoa, ${ }^{d}$ Francisco Carvajal Ramos, ${ }^{e} \mathrm{~J}$. Félix Armando Soltero Martínez ${ }^{\mathrm{c}}$ \\ and Yahya Rharbi ${ }^{\star a b}$
}

Vectorization has experienced significant development over the last few years and has been used to control the distribution of active ingredients to a target by their association with a vector. However, controlled drug delivery suffers from "burst release" as the drugs are released before the targeted site. Very few studies have examined the collective mechanisms of fission-fusion on micelles in the transport and expulsion of active ingredients. Endocytosis and exocytosis of cells are examples of fusion and fission in biological matter. Understanding these dynamics becomes crucial for the design and the control of new materials and new processes effective in controlled drug delivery. In this work, a study of the exchange dynamics between amphiphilic block copolymers and lipid membranes for vectorization of hydrophobic molecules using a fluorescence technique is presented. A highly hydrophobic alkylated pyrene, $\mathrm{PyC}_{18}$, is used as a fluorescent probe that can be exchanged between amphiphilic block copolymer micelles and liposomes via different mechanisms. It is demonstrated that the exchange dynamics evaluated for different liposome concentrations is a collective mechanism characterized by having two rate constants.

\section{Introduction}

Nowadays, the specific delivery of active ingredients, known as vectorization, represents a great challenge in therapeutic research. ${ }^{1-3}$ This process has been used to control the distribution of active ingredients such as proteins, genes (for gene therapy) and drugs to a target by association with a vector. ${ }^{4-6}$ It allows increasing the therapeutic effects of the drug and may reduce the side effects. ${ }^{4-6}$ Vectorization may be achieved by chemical, physical or biological methods, and is considered an important process in cases where the drug is chemically unstable or presents weak characteristics pharmacokinetics. ${ }^{7,8}$ Vectorization proposes several benefits such as increasing the therapeutic effect, decreasing toxicity caused by the active principle, increasing half-life of the active ingredient and releasing the active ingredient in time among others., ${ }^{\mathbf{9 1 0}}$

aUniv. Grenoble Alpes, LRP, F-3800o Grenoble,France.E-mail: monik_ayanami@ hotmail.com; yahya.rharbi@univ-grenoble-alpes.fr

${ }^{b} \mathrm{CNRS}$, LRP, F-38000 Grenoble, France

'Universidad de Guadalajara, Departamento de Ingeniería Química, Blvd. M. García Barragán \#1451, C.P. 44430, Guadalajara, Jalisco, Mexico

${ }^{d}$ Universidad de Guadalajara, Departamento de Química, Blvd. M. García Barragán \#1451, C.P. 44430, Guadalajara, Jalisco, Mexico

${ }^{e}$ Universidad de Guadalajara, CUTonalá, Departamento de Ingenierías, Nuevo Periférico \#555 Ejido San José Tatepozco, C.P. 45425, Tonalá, Jalisco, Mexico

$\dagger$ Electronic supplementary information (ESI) available. See DOI: $10.1039 / \mathrm{c} 8 \mathrm{ra0} 08903 \mathrm{e}$
Three main types of physical vectors are known: liposomes, microparticles and nanoparticles. ${ }^{\mathbf{1 1}, 12}$ The main difference between microparticles and nanoparticles is the size of both structures, i.e. greater or less than $1 \mu \mathrm{m}$, respectively. ${ }^{\mathbf{1 3 , 1 4}}$ Nanoparticles formed with copolymers have been widely studied and used in the preparation of drug and gene delivery systems. ${ }^{15,16}$ Several kinds of copolymers such as amphiphilic block copolymers, graft copolymers and crosslinked copolymers, among others, are of great interest for controlled drug delivery applications. ${ }^{17-25}$ Amphiphilic block copolymers are known by their efficiency during drug delivery processes with multiple effects. ${ }^{26,27}$ The incorporation of drugs into the micelles core formed by these copolymers may lead to an increment of solubility, metabolic stability and circulation time for the drug. ${ }^{28}$ In this manner, the core-shell design of the micelles is crucial for their effectiveness in drug delivery. ${ }^{29}$ It is worth to mention that the core is a water-incompatible compartment able to receive the incorporation of several therapeutic reagents, that is segregated from the aqueous exterior by the hydrophilic chains of the shell. ${ }^{30}$ Lipophilic drugs solubilization by copolymers can be done by hydrophobic and/or covalent interactions between a part of the polymer structure and the drug. ${ }^{15}$ Recently, the interactions of the triblock copolymer unimers with multidrug-resistant cancer cells have been studied, resulting in the sensitization of these cells with respect to various anticancer agents. ${ }^{31-33}$ 
On the other side, liposomes are different from the microparticles and nanoparticles due to their nature and composition. It is noteworthy that the liposomes are vesicles consisting of concentric membranes with single or multiple phospholipid bilayers used as the simplest models of cells. ${ }^{34,35}$ They are formed spontaneously as a result of lipid-water interactions. Various techniques exist for preparing liposomes, which can allow obtaining vesicles with different sizes, internal volumes and encapsulation capacities. ${ }^{36,37}$ The three principal kinds of liposomes are the following: small unilamellar vesicles (SUVs) with sizes from 20 to $100 \mathrm{~nm}$, large unilamellar vesicles (LUVs) with sizes from 100 to $500 \mathrm{~nm}$ and giant unilamellar vesicles (GUVs) with sizes from 0.5 to $100 \mu \mathrm{m}$, which are generally studied as over-simplified models of biological cells and can be directly observed by optical microscopy. ${ }^{38}$ A giant unilamellar vesicle (GUV) has a similar basic structure of all biological cells, since a vesicle membrane imitates the self-closed lipid matrix of the plasma membrane.

Vectorization has undergone significant development in the last few years. ${ }^{39,40}$ Currently, molecules used in chemotherapy are generally hydrophobic and require a vectorization process to be transported to the targeted cell. ${ }^{41,42}$ However, this controlled release of drugs suffers from a phenomenon known as "burst release", in which the active ingredient is released before reaching its target. ${ }^{43-45}$ Micelles made of amphiphilic block copolymers with a nanoscale size between 5 and $100 \mathrm{~nm}$, have an inner core formed by the hydrophobic blocks creating a space for the solubilization, storage, controlled delivery and protection of hydrophobic drugs. ${ }^{15}$ Many studies have been performed in order to develop a variety of nanostructures, including micelles, polymersomes and hydrogels for an efficient drug delivery. ${ }^{15,31,46,47}$ However, very few studies have examined the collective mechanisms as fission-fusion on micelles in the transport and expulsion of active ingredients. Understanding these dynamics during specific stimuli for the release of the active ingredient becomes crucial for the design and the control of new materials and new processes effectives in controlled drug delivery.

The focus of this paper is related to the study of the dynamics between amphiphilic triblock copolymers micelles and liposomes for the vectorization of hydrophobic molecules using a fluorescence technique that has been previously used to characterize, analyze and quantify collective dynamics between amphiphilic copolymers micelles. ${ }^{48}$ The studied system in this work is composed by liposomes representing cells (GUVs), amphiphilic block copolymer micelles of P104 Pluronic modeling the transporting vehicles including highly hydrophobic alkylated pyrene, $\mathrm{PyC}_{18}$, representing the active ingredient introduced into the micelles. The role of liposomes concentration and amphiphilic triblock copolymer concentration is investigated in order to control the vectorization dynamics between micelles to liposomes. The exchange dynamics of the fluorescent probe between amphiphilic block copolymer micelles and liposomes is discussed in terms of the kinetic constant $k_{\text {decay }}$, obtained from the reciprocal of the exchange time constant, as a function of liposomes concentration.

\section{Experimental section}

\subsection{Materials}

Triblock copolymer Pluronic ${ }^{\circledR}$ P104, $\left[(\mathrm{PEO})_{27}-(\mathrm{PPO})_{61}-(\mathrm{PEO})_{27}\right]$ (Scheme 1a), with a molecular weight of $5900 \mathrm{~g} \mathrm{~mol}^{-1}$, was provided by the BASF Company.

$\mathrm{P} 104 / \mathrm{H}_{2} \mathrm{O}$ solutions were prepared with water obtained through a Millipore Milli-Q purification system. $\mathrm{L}-\alpha$-Phosphatidylcholine (PC) from egg yolk (1,2-diacyl-sn-glycero-3phosphocholine $\mathrm{C}_{42} \mathrm{H}_{82} \mathrm{NO}_{8} \mathrm{P}$ ), with a molecular weight of $776 \mathrm{~g} \mathrm{~mol}^{-1}$ was provided by Sigma Aldrich and was used as received (Scheme 1b). Organic solvents chloroform (Sigma Aldrich, $\geq 99 \%$ ) and methanol (Sigma Aldrich, 99.8\%) were used as received. Pyrene probes (Sigma Aldrich) were used as received and pyrenyl-octadecanone $\mathrm{C}_{34} \mathrm{H}_{44} \mathrm{O}\left(\mathrm{PyC}_{18}\right)$ (Scheme 1c) was prepared using a Friedel-Crafts acylation of pyrene with stearoyl chloride in dichloroethane in the presence of aluminum chloride $\left(\mathrm{AlCl}_{3}\right)^{50}$

\subsection{Solutions preparation}

Micellar solutions of triblock copolymer P104 were prepared by mixing P104 with water under gentle stirring at room temperature for $24 \mathrm{~h}$, then, the solution was stored for more than $24 \mathrm{~h}$ at $37{ }^{\circ} \mathrm{C}$ to form spherical micelles at equilibrium. The solubilization of the probe $\mathrm{PyC}_{18}$ in the copolymer micelles was carried out following the procedure described by Rharbi et $a l .{ }^{48}$ For that purpose, $\mathrm{PyC}_{18}$ probe was solubilized in $\mathrm{P} 104$ micelles by mixing the aqueous copolymer solution $\left(10 \mathrm{mg} \mathrm{mL} \mathrm{mL}^{-1}\right)$ with $\mathrm{PyC}_{18}$ at $75{ }^{\circ} \mathrm{C}$. The solutions were stirred vigorously for $10 \mathrm{~min}$ in a Vortex Genie 2 model G 650 at its maximum frequency $(>10$ $\mathrm{Hz}$ ). The solution was then cooled back to $37^{\circ} \mathrm{C}$ to form micelles including the fluorescent probe. This procedure was repeated several times. The undissolved probe was removed by filtering the solution at $37^{\circ} \mathrm{C}$ when needed. In complementary experiments, pyrene was solubilized in the P104 micelles by mixing P104 solutions in the presence of small amounts of pyrene under gentle stirring for more than $24 \mathrm{~h}$ at $37^{\circ} \mathrm{C}$. The undissolved pyrene was removed by filtration using a Millex® GS 0.22 $\mu \mathrm{m}$ filter by Millipore.

The liposomes suspensions were prepared following the procedure reported elsewhere. ${ }^{38}$ The phospholipid was first

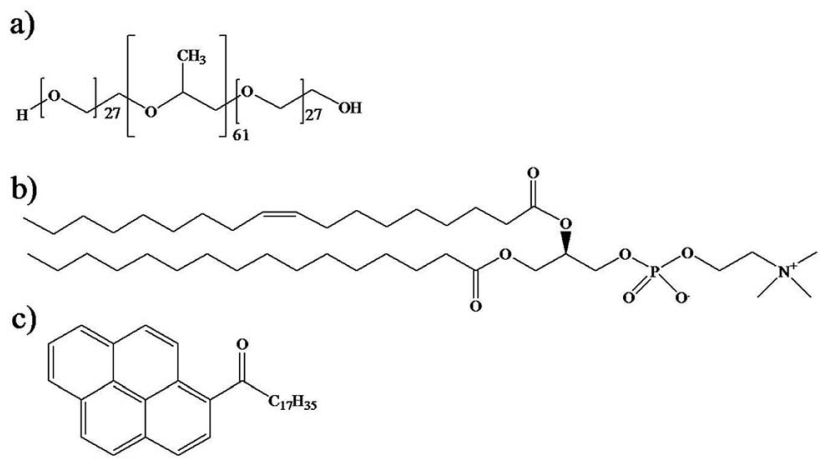

Scheme 1 Chemical structures of (a) triblock copolymer Pluronic ${ }^{\circledR}$ P104, (b) L- $\alpha$-phosphatidylcholine and (c) hydrophobic fluorescent probe $\mathrm{PyC}_{18}$. 
dissolved in chloroform and methanol with a ratio of $2: 1$, respectively, and the water was added drop wise to the solution under gentle stirring. The organic solvent was removed through evaporation during 5 days at $37{ }^{\circ} \mathrm{C}$. The total volume of the solution was kept constant throughout the solvent evaporation process by adding water progressively using self-controlled mechanism to compensate the evaporated water. The evaporation was stopped when no solvent was present. This procedure allowed obtaining a suspension containing giant unilamellar vesicles (GUVs), with a concentration of $25 \mathrm{mg} \mathrm{mL}^{-1}$ (information available in ESI, Fig. S1 $\dagger$ ). The liposomes suspensions were stored at $4{ }^{\circ} \mathrm{C}$. Large unilamellar vesicles (LUVs) were obtained by extrusion of a suspension of GUVs, using a $0.22 \mu \mathrm{m}$ filter (Millex® GS by Millipore). LUVs suspensions were prepared from the initial GUVs suspension in order to preserve the lipid composition and to be able to perform dynamic light scattering measurements in convenient conditions. ${ }^{49}$

\subsection{Characterization methods}

Dynamic light scattering (DLS) measurements were performed using a Malvern Zetasizer 5000 apparatus equipped with a 7132 multibit correlator and a multiangle goniometer. The light source was a He-Ne $5 \mathrm{~mW}$ laser with a wavelength of $632.8 \mathrm{~nm}$. The light scattering intensity was measured through a $400 \mu \mathrm{m}$ pinhole. DLS measurements were carried out at several scattering angles between $35^{\circ}$ and $135^{\circ}$. The corresponding hydrodynamic radius was calculated using the Stokes-Einstein equation for spherical particles. $\zeta$-Potential measurements were performed in a Malvern Zetasizer NanoZS at a temperature of $37{ }^{\circ} \mathrm{C}$. The results are the average of 5 runs. The instrument measured the electrophoretic mobility of the particles and converted it to the $\zeta$-potential using the classical Smoluchowski expression. Microscopy images of GUVs were acquired with a confocal microscope Leica S440. UV-Vis measurements were performed in a HP 8452 UV-Vis Spectrophotometer at room temperature in order to calculate $\mathrm{PyC}_{18}$ concentration in the P104 triblock copolymer solutions (with the $A_{380}$ value and $\varepsilon=$ $\left.7.454 \times 10^{4}\right)$. $\zeta$-Potential and DLS data is analyzed in terms of the P104 micelles concentration and the lipids concentration, i.e. $[\mathrm{P} 104] /[$ lipid].

\subsection{Kinetic experiments}

Fluorescence kinetic measurements were carried out in a Jobin Yvon Spectrometer Fluorolog III (2-2) in the S/R mode. P104/ $\mathrm{H}_{2} \mathrm{O}$ solutions were used at concentrations and at a temperature above the critical conditions at which spherical micelles are formed. The experimental conditions were selected close to the physiological conditions, i.e. controlled $\mathrm{pH}$ of 6.5 and a temperature of $37{ }^{\circ} \mathrm{C}$, in order to facilitate the understanding of micellar drug delivery vehicles interactions with phospholipid membranes. These experiments were performed by mixing P104 micelles containing $\mathrm{PyC}_{18}$ with a suspension of GUVs free of probe in a cylindrical pyrex cell (1 $\mathrm{cm}$ of diameter). The measurement cell was placed in a temperature controlled cell holder at $37 \pm 0.1{ }^{\circ} \mathrm{C}$.
Measurements were performed with liposomes suspensions at $25 \mathrm{mg} \mathrm{mL}^{-1}$ and $\mathrm{P} 104$ micelles solutions with $\mathrm{PyC}_{18}$ at $10 \mathrm{mg}$ $\mathrm{mL}^{-1}$, at different ratios, to obtain a final concentrations of $3 \mathrm{mg} \mathrm{mL}{ }^{-1}$ for the P104 solution and 6, 8, 10 and $15 \mathrm{mg} \mathrm{mL}^{-1}$ for the liposomes suspensions. The measurements were performed in the emission mode by fixing the excitation wavelength at $344 \mathrm{~nm}$ and scanning the emission wavelength between $360 \mathrm{~nm}$ and $600 \mathrm{~nm}$. This scan was repeated each $3 \mathrm{~min}$ in the early kinetic time and then each few hours at the end of the kinetic procedure, which lasted one week. The fluorescence spectrum shows two signals, identified as monomer species (366 nm $<I_{\text {MON }}<425 \mathrm{~nm}$ ) and excimer species (440 nm $\left.<I_{\mathrm{EX}}<550 \mathrm{~nm}\right)$. The excimer $I_{\mathrm{EX}}$ was calculated by integrating the intensity peak between $440 \mathrm{~nm}$ and $550 \mathrm{~nm}$ and the monomer one between $366 \mathrm{~nm}$ and $425 \mathrm{~nm}$. The existence of this excimer emission band supposes that P104 micelles are bearing two or more $\mathrm{PyC}_{18}$ molecules. ${ }^{48}$ Before analysis of the spectrum, possible contribution of liposomes was taken into consideration. For that purpose, liposomes solutions at different concentrations were studied in order to remove any liposomes signal contribution to the emission spectra. A special program using OriginPro software was developed in order to subtract the intensity signal of liposomes suspensions from each emission spectra and to integrate the excimer and monomer intensity peaks. The evolution of the acquired spectra as a function of time was quantified by calculating the ratio of the excimer to monomer intensity signals.

Other kinetic experiments were performed by measuring the lifetime evolution of $\mathrm{PyC}_{18}$ by using a homemade single photon counting spectrometer. The excitation wavelength was $344 \mathrm{~nm}$ and the emission $380 \mathrm{~nm}$. Spectrums were taken each $30 \mathrm{~min}$. These measurements were performed by mixing a P104 solution containing small amounts of $\mathrm{PyC}_{18}$ with liposomes solutions. The excimer of this solution was chosen to be small enough to be able to quantify the pyrene lifetime from the decay of the signal. The lifetime was calculated by fitting the decays with a single exponential expression removing the first excimer contribution at the beginning of the spectrum.

\section{Results and discussion}

\subsection{Characterization of P104 micelles, liposomes and their mixtures}

Shape information about the obtained P104 micelles in water was obtained from the combination of the light scattering intensity and the hydrodynamic radius by performing dynamic light scattering (DLS) measurements at equilibrium in a temperature range from 10 to $64{ }^{\circ} \mathrm{C} . .^{51,52}$ The variation of the total scattering intensity with temperature was used to estimate the critical micellar temperature (CMT), which was found to decrease with increasing P104 copolymer concentration..$^{53}$ The CMT of these micelles was estimated from the increase of the scattering intensity as micelles form. It was found to be $26^{\circ} \mathrm{C}$ at $10 \mathrm{mg} \mathrm{mL}{ }^{-1}$, which is in good agreement with the reported values in the literature. ${ }^{54}$ Between 26 and $54{ }^{\circ} \mathrm{C}$, the average hydrodynamic radius of the formed micelles is $11.4 \mathrm{~nm}$ (Fig. 1a). ${ }^{53,54}$ Further analysis of the light scattering suggest that 
a)

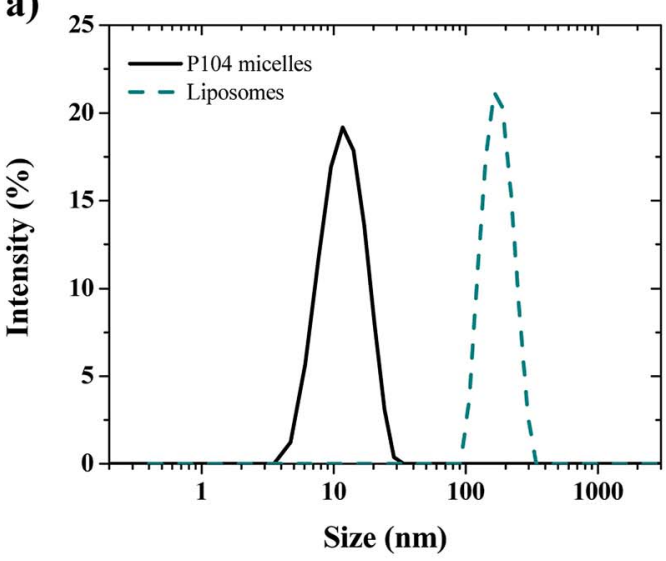

b)

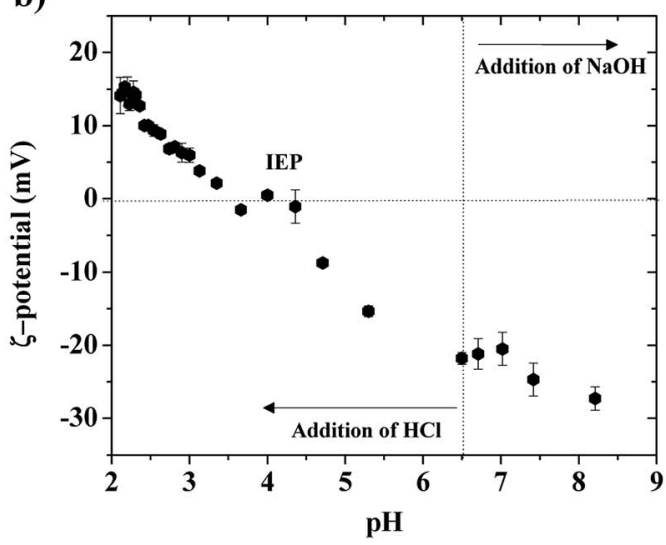

Fig. 1 (a) Dynamic light scattering measurements for P104 micelles (3 mg mL ${ }^{-1}, D_{H}=11.4 \mathrm{~nm}, \mathrm{PDI}=0.11$ ) and liposomes, (LUVs with a concentration of $\left.10 \mathrm{mg} \mathrm{mL}^{-1}, D_{\mathrm{H}}=170 \mathrm{~nm}, \mathrm{PDI}=0.15\right)$ (b) $\zeta$ potential variation of LUVs as a function of $\mathrm{pH}$. The isoelectric point (IEP) is obtained around a $\mathrm{pH}=4.0$.

the obtained P104 micelles are spherical, as shown in the literature. $^{.33,54}$

The net charge of P104 micelles was then evaluated through $\zeta$-potential measurements at a temperature of $37^{\circ} \mathrm{C}$ and a pH of 6.5 , obtaining a value of around $-6 \pm 2 \mathrm{mV}$, which reveals a slight negative charge due mostly to traces of sodium or potassium hydroxide used as catalysts during the oxyalkylation step of P104 triblock copolymer synthesis. ${ }^{53}$

Dimensions of LUVs having a concentration of $25 \mathrm{mg} \mathrm{mL}^{-1}$ and a $\mathrm{pH}=6.5$ were determined, as a first approximation, through dynamic light scattering measurements at $37{ }^{\circ} \mathrm{C}$ (Fig. 1a). For this, a polydisperse suspension of liposomes having an average hydrodynamic diameter of $450 \pm 100 \mathrm{~nm}$ was firstly identified, corresponding to a giant unilamellar vesicles (GUVs) suspension. ${ }^{38}$ Then, after extrusion of GUVs suspensions, LUVs having diameters of $170 \mathrm{~nm}$ were obtained (Fig. 1a, PDI: 0.150). The evolution of liposomes size (GUVs and LUVs) with time was monitored by performing DLS measurements during at least one week, showing that the obtained dimensions were stable at these experimental conditions (concentration, $\mathrm{pH}$ and temperature).

The electric charge of LUVs and GUVs was then studied through $\zeta$-potential measurements, which reveal that their structure is sensitive to $\mathrm{pH}$ and ionic strength, as previously reported..$^{55-58}$ This is considered an important parameter since charge affects both the particle stability and liposomal pharmacology ${ }_{.}^{55}$ Fig. $1 \mathrm{~b}$ shows the $\zeta$-potential dependence with $\mathrm{pH}$ of LUVs suspension. The $\zeta$-potential increases with the addition of $\mathrm{HCl}$, which decreases the $\mathrm{pH}$ of the suspension. The isoelectric point (IEP) is found when $\zeta$-potential $=0 \mathrm{mV}$ around a pH of 4.0, in good agreement with the literature. ${ }^{57}$ Then, the $\zeta$ potential becomes positive and reaches a constant value of $+14 \mathrm{mV}$ at a pH around 2.0. When $\mathrm{pH}$ decreases, the dissociation of the phosphate acid and carboxyl groups is reduced and the relative positive contribution of the quaternary amino group increases. ${ }^{58}$ On the other side, the $\zeta$-potential decreases with the addition of $\mathrm{NaOH}$ until reaching a constant value of around $-30 \mathrm{mV}$ at a $\mathrm{pH}$ of 8 , which was attributed to the complete dissociation of the phosphate and carboxyl groups of the lipids. ${ }^{58}$ At a $\mathrm{pH}$ of 6.5 , corresponding to the $\mathrm{pH}$ of the liposomes preparation (LUVs), $\zeta$-potential is negative and has a value around to $-22 \mathrm{mV}$, in good agreement with the values previously reported by several authors. ${ }^{55,56}$ In this study, the $\mathrm{pH}$ value of GUVs suspensions is maintained at $\mathrm{pH}=6.5$, where the membrane is negatively charged and stable. ${ }^{55}$

\subsection{Structure and interactions of P104 micelles and liposomes mixtures}

Since P104 micelles are weakly negatively charged due to catalysts residues and liposomes are stable and highly negatively charged, the electrostatic interactions between both particles were studied through $\zeta$-potential measurements. ${ }^{53} \mathrm{Fig} .2$ shows the $\zeta$-potential dependence with the ratio given by P104 and lipids concentration, i.e. [P104]/[lipid], assuming that about half of the lipid heads are outside the liposome and contribute to the interactions with the external medium. Different amounts of P104 micelles with a concentration interval from 0 up to $10 \mathrm{mg} \mathrm{mL} \mathrm{m}^{-1}$ were mixed with a liposomes suspension with an initial concentration of $25 \mathrm{mg} \mathrm{mL}{ }^{-1}$, resulting on different [P104]/[lipid] ratios.

It is possible to observe that the $\zeta$-potential slightly decreases with the increase of the amount of P104 micelles in the mixture,

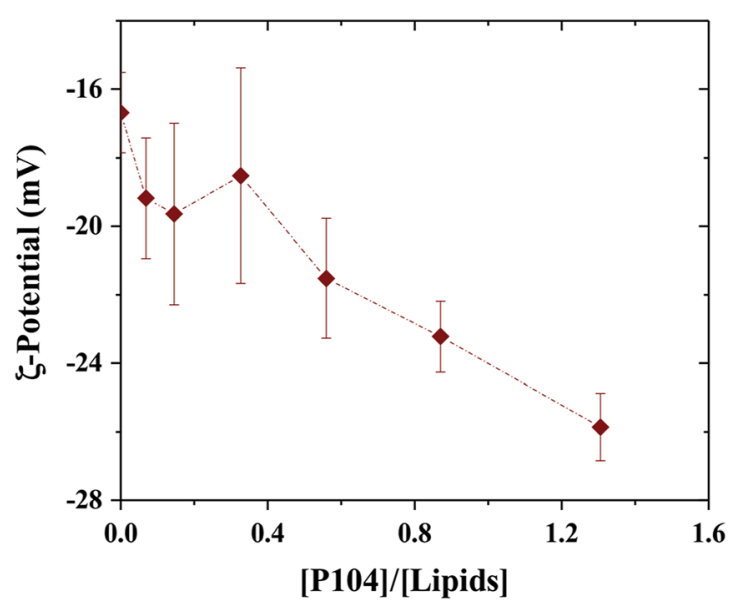

Fig. $2 \zeta$-Potential variation with the [P104]/[lipid] ratio. Measurements were performed at a constant temperature of $37^{\circ} \mathrm{C}$ and a $\mathrm{pH}=6.5$. 
suggesting the presence of weak electrostatic interactions between micelles and the lipidic membrane. These measurements show clearly that part of the P104 micelles interact with the liposome membrane, leading to reduction of the total net charges.

The obtained structures from the mixtures between P104 micelles and liposomes were studied through DLS measurements by following the evolution of the hydrodynamic diameter of LUVs (selected to perform this study due to their size, suitable for DLS measurements) suspensions having different concentrations with the addition of various amounts of P104 micelles. The average hydrodynamic diameter for all the mixtures was found to be $160 \pm 40 \mathrm{~nm}$, remaining almost constant to the initial diameter of the liposome (information available in ESI, Fig. S2 $\dagger$ ). Then, the presence of P104 micelles does not induce any significant modification of the hydrodynamic diameter of liposomes, which remain almost constant.

P104 micelles may undergo partitioning into unimers in water and liposomes suspensions. Hence, the fraction of P104 micelles in water is taken as the critical micellar concentration (CMC). The partition of P104 micelles in the liposome suspension can be estimated from the excimer and the monomer formation of $\mathrm{PyC}_{18}$ through fluorescence measurements. When a P104 solution containing micelles is mixed with a liposomes suspension, the total concentration of P104 is diluted. Some P104 micelles will interact with liposomes in different ways and another part of the copolymer will go into water, since the CMC gets closer. The mechanism of interaction was studied using P104 micelles including a fluorescent probe. The evolution of the $\mathrm{PyC}_{18}$ emission spectra contained in P104 solutions having different concentrations mixed with a liposome suspension having a fixed concentration of $25 \mathrm{mg} \mathrm{mL}^{-1}$ was studied and is illustrated in Fig. 3a. Here, it is possible to observe a decrease in the excimer band, located at $\lambda_{\mathrm{EX}}=480 \mathrm{~nm}$ and an increase in the monomer band, located at $\lambda_{\mathrm{MON}}=376 \mathrm{~nm}$, decreasing the P104 micelles concentration in the final solution. The existence of the excimer emission band at $480 \mathrm{~nm}$ supposes that P104 micelles are bearing two or more $\mathrm{PyC}_{18}$ molecules. ${ }^{48}$ Then, when $\mathrm{P} 104$ micelles with $\mathrm{PyC}_{18}$ are mixed with $\mathrm{PyC}_{18}$ free liposomes suspension, the evolution of the spectrum infers an exchange of $\mathrm{PyC}_{18}$ between micelles and liposomes, leading to P104 micelles bearing only one $\mathrm{PyC}_{18}$ probe ${ }^{48}$ before reaching the CMC.

The evolution of the $\mathrm{PyC}_{18}$ emission spectra contained in a P104 solution in water at different concentrations was also studied to compare the variation on the excimer and monomer bands to the results obtained for the $\mathrm{PyC}_{18}$ contained in $\mathrm{P} 104$ micelles and mixed with a liposomes suspension. This variation was quantified by using the ratio between the monitored intensities, $I_{\mathrm{MON}} / I_{\mathrm{EX}}$, for P104 micelles and liposomes mixtures and for the dilution of P104 micelles in water. Fig. 3b shows the obtained results in terms of the reciprocal of P104 triblock copolymer concentration. In both cases it is possible to identify a change localized around the P104 concentration of $0.67 \mathrm{mg}$ $\mathrm{mL}^{-1}$ in water and around the $\mathrm{P} 104$ concentration of $0.53 \mathrm{mg}$ $\mathrm{mL}^{-1}$ in liposome suspensions, related to the CMC of the amphiphilic block copolymer at the temperature of $37^{\circ} \mathrm{C}$, in good agreement with previous results. It is then possible to say
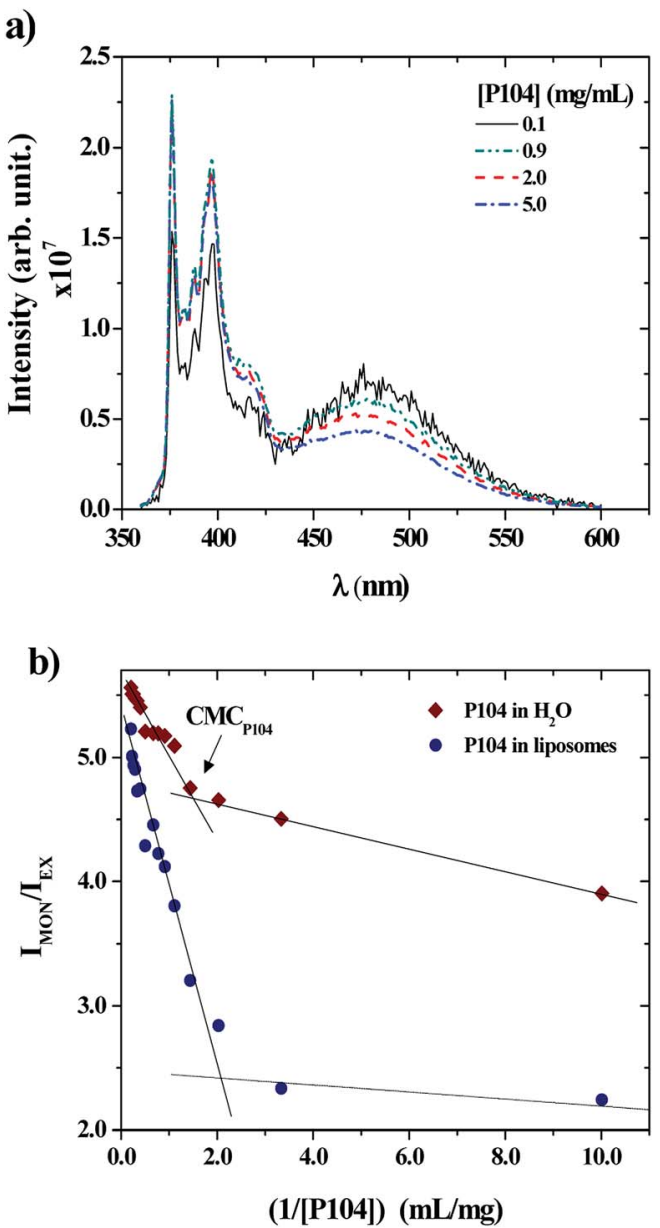

Fig. 3 (a) Emission spectra of $\mathrm{PyC}_{18}$ in $\mathrm{P} 104$ aqueous solutions mixed with GUVs suspensions evaluated at different concentrations of P104 at a temperature of $37{ }^{\circ} \mathrm{C}$. (b) $\mathrm{CMC}$ evaluation of P104 triblock copolymer in water and in liposomes suspension at a constant $\mathrm{pH}=$ 6.5 and a temperature of $37^{\circ} \mathrm{C}$.

that the value of $\mathrm{P} 104 \mathrm{CMC}$ at $37^{\circ} \mathrm{C}$ remains almost constant in the liposomes environment.

\subsection{Vectorization dynamics between liposomes and P104}

Dynamics between P104 amphiphilic triblock copolymer, selected as vectors, and liposomes were studied through fluorescence measurements. Fig. 4a shows the spectra of liposomes suspension having a concentration of $25 \mathrm{mg} \mathrm{mL}^{-1}$ and the emission spectra of $\mathrm{PyC}_{18}$ in an aqueous solution of $\mathrm{P} 104$ with a concentration of $10 \mathrm{mg} \mathrm{mL} \mathrm{m}^{-1}$ mixed with the liposomes suspension with and without the subtraction of the emission spectrum of liposomes (initial value without fluorescent probe inclusion). In this study, an excitation wavelength of $344 \mathrm{~nm}$ was applied. The fluorescence spectra of P104 micelles containing more than one molecule of $\mathrm{PyC}_{18}$ exhibit an emission excimer band at $480 \mathrm{~nm}$ and an emission monomer band at $376 \mathrm{~nm}$. L- $\alpha$-Phosphatidylcholine liposomes present a fluorescence spectrum in the wavelength range between 350 and $600 \mathrm{~nm}$ with a characteristic peak around $425 \mathrm{~nm}$. This response is related to impurities of liposomes suspensions. The intensity signal obtained for liposomes suspension is 

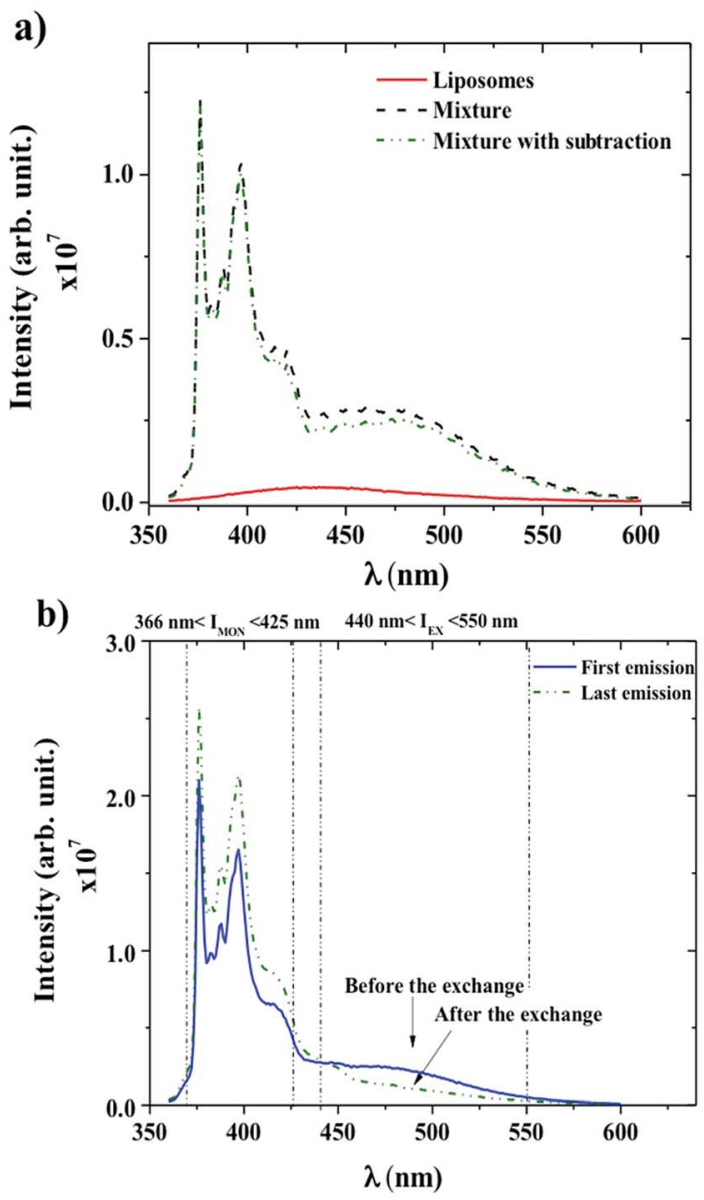

Fig. 4 (a) Emission spectra of liposomes suspension at a concentration of $25 \mathrm{mg} \mathrm{mL}^{-1}$ and emission spectra of $\mathrm{PyC}_{18}$ in an aqueous solution of P104 with a concentration of $10 \mathrm{mg} \mathrm{mL}^{-1}$ mixed with liposomes with and without the subtraction of the emission spectrum of liposomes, both measured at a temperature of $37^{\circ} \mathrm{C}$ and at a $\mathrm{pH}=$ 6.5. (b) Emission spectra of $\mathrm{PyC}_{18}$ in a mixture of $3 \mathrm{mg} \mathrm{mL}^{-1} \mathrm{P} 104$ aqueous solution mixed with a liposomes suspension (right after mixing) before and 4 days after the exchange, both measured at a temperature of $37{ }^{\circ} \mathrm{C}$. The final concentrations of P104 and liposomes in the mixture are $3 \mathrm{mg} \mathrm{mL}^{-1}$ and $17.5 \mathrm{mg} \mathrm{mL}^{-1}$, respectively.

considerably lower than the intensity signal obtained for P104 micelles containing $\mathrm{PyC}_{18}$, however, it is important to remove the emission spectra of liposomes. In this way, in further analysis, the emission spectrum of liposomes will be subtracted from $\mathrm{PyC}_{18}$ in $\mathrm{P} 104$ micelles emission spectra in order to remove any other contribution to the fluorescence intensity that gives us the information about the exchange dynamics following $\mathrm{PyC}_{18}$ bands evolution. ${ }^{48,59-61}$ The contribution of the liposome intensity signal depends on its concentration, while increasing liposomes suspension concentration the intensity increases, however, nevertheless, at low concentrations, the signal remains negligible.

Fig. $4 \mathrm{~b}$ shows the emission spectra of $\mathrm{PyC}_{18}$ in an aqueous solution of P104 with a concentration of $3 \mathrm{mg} \mathrm{mL}^{-1}$ before and after the exchange with a liposomes suspension at concentration of $17.5 \mathrm{mg} \mathrm{mL}^{-1}$ and a constant $\mathrm{pH}$ of 6.5. The emission spectrum presents a broad excimer emission with a fluorescence signal between 440 and $550 \mathrm{~nm}$, and monomer fluorescence at $376-400 \mathrm{~nm}$, as for the case of $\mathrm{PyC}_{18}$ spectrum in amphiphilic block copolymer micelles. ${ }^{48}$ The presence of the excimer emission at $480 \mathrm{~nm}$ infers the presence of micelles containing two or more $\mathrm{PyC}_{18}$ molecules. The response of the monitored emission 4 days after the mixture of P104 micelles and liposomes shows a decrease in the value of the excimer and an increase of the monomer intensity. This spectrum evolution infers an exchange of $\mathrm{PyC}_{18}$ between $\mathrm{P} 104$ micelles and liposomes, which mechanism will be detailed in the following.

Fig. $5 \mathrm{a}$ and $\mathrm{b}$ show the time-scan analysis for the evolution of the monomer and the excimer intensities, respectively, after mixing $\mathrm{P} 104$ containing $\mathrm{PyC}_{18}$ with liposomes suspension. Both $I_{\mathrm{EX}}$ and $I_{\mathrm{MON}}$ increase during the early kinetic time and reached a maximum. Then, $I_{\mathrm{EX}}$ decreases for all liposomes concentrations, showing the efficient exchange of $\mathrm{PyC}_{18}$ between $\mathrm{P} 104$ micelles and liposomes, which infers the transfer of $\mathrm{PyC}_{18}$ transported by $\mathrm{P} 104$ onto liposomes membrane. The $I_{\mathrm{MON}}$, instead, decreases very slightly for 6 and $8 \mathrm{mg} \mathrm{mL}^{-1}$ after reaching the maximum, then for $10 \mathrm{mg} \mathrm{mL}^{-1}$, it remains nearly constant and finally, for $15 \mathrm{mg} \mathrm{mL}^{-1}$, it continues increasing very slowly until reaching a constant behavior.
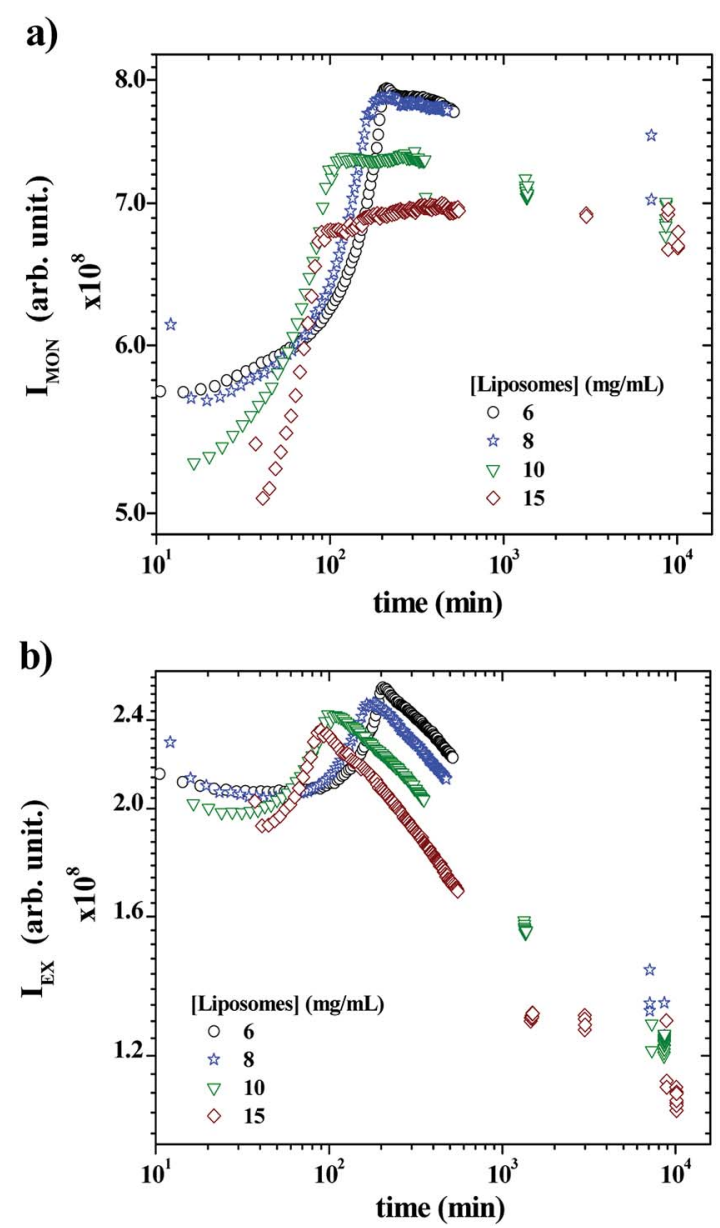

Fig. 5 (a) / IMON decay and (b) / EX decay as a function of time obtained during the exchange of a mixture containing $3 \mathrm{mg} \mathrm{mL}^{-1} \mathrm{P} 104$ micelles with $\mathrm{PyC}_{18}$ and liposomes suspensions with the following concentrations: $6,8,10$ and $15 \mathrm{mg} \mathrm{mL}^{-1}$. The measurement temperature is $37^{\circ} \mathrm{C}$ at a $\mathrm{pH}=6.5$. 
In fact, during the exchange kinetic, the decrease of $I_{\mathrm{EX}}$ should be accompanied with an increase in $I_{\mathrm{MON}}$. Yet the magnitude of growth of the monomer intensity is usually much lower than that of the decrease of the excimer particularly for low average number of pyrene per micelles $(\langle n\rangle)$, which is the case here. Since the exchange kinetic is very slow in the present experiment, the growth of $I_{\text {MON }}$ is most likely counterbalanced with the slight photobleaching that leads to stabilization of $I_{\text {MON }}$ particularly for long time. Because the ratio $I_{\mathrm{EX}} / I_{\mathrm{MON}}$ varies linearly with $\langle n\rangle^{\mathbf{6} 2}$ the exchange kinetic is exclusively quantified using $I_{\mathrm{EX}} / I_{\mathrm{MON}}$.

The early increase of the intensities $\left(I_{\mathrm{EX}}\right.$ and $\left.I_{\mathrm{MON}}\right)$ until reaching a maximum is most likely due to a change on the $\mathrm{PyC}_{18}$ environment within the P104 micelles rather than a change in the excimer quenching process. One possible explanation of this increase is the reduction of the oxygen concentration in P104 micelles, leading to an increase of the total fluorescence intensity. Because of the relatively long life time of pyrene (from 200 to $500 \mathrm{~ns}$ ) oxygen is an efficient quencher for pyrene fluorescence. In this case, the growth of fluorescence can be quantified using the Stern-Volmer equation $\left(I_{\mathrm{f}}^{0} / I_{\mathrm{f}}=1+k_{\mathrm{q}} \tau_{0}[Q]\right.$, where $I_{\mathrm{f}}^{0}$ is the intensity without quencher, $I_{\mathrm{f}}$ is the intensity with quencher, $k_{\mathrm{q}}$ is the quencher rate coefficient, $[Q]$ is the quencher concentration and $\tau_{0}$ is the lifetime of the emissive excited state of the chemical species). According to this equation, the fluorescence intensity growth with time corresponds to the reduction of partial oxygen pressure or its solubility within the P104 micelles. One possible explanation of the origin of this phenomenon will be discussed later. When increasing liposomes concentration, the overall growth decays shift to lower times, as well as the position of the maximum for both $I_{\mathrm{EX}}$ and $I_{\mathrm{MON}}$. This means that the kinetic of this phenomenon is activated by the increase of the presence of liposomes in the mixture. The time $\left(\tau_{\max }\right)$ corresponding to the maximum of $I_{\mathrm{EX}}$ and $I_{\mathrm{MON}}$ can be used to quantify this decay.

Fig. 6 shows that the variation of the kinetic constant $k_{\text {exchange }}=1 / \tau_{\max }$ for both the maximum of both $I_{\mathrm{EX}}$ and $I_{\mathrm{MON}}$

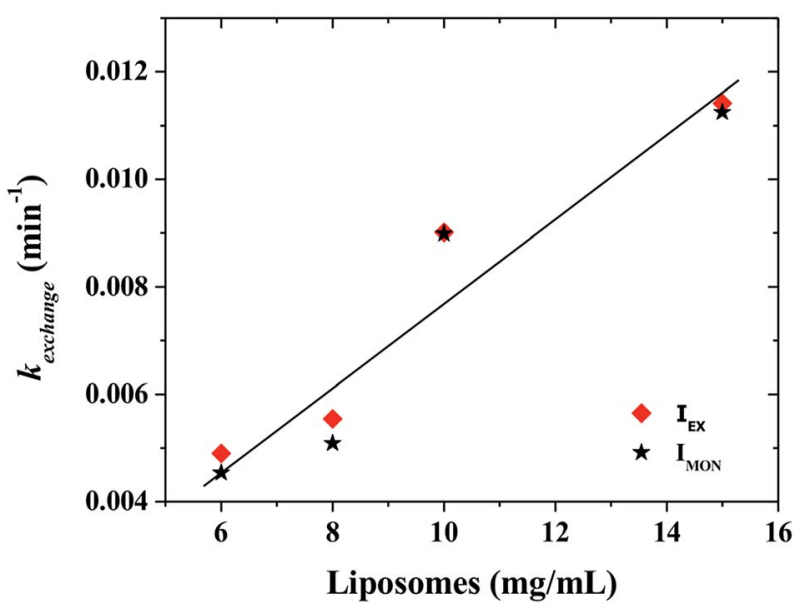

Fig. 6 Variation of the kinetic constant $k_{\text {exchange }}\left(1 / \tau_{\max }\right)$ obtained at the maximum intensity reached after the increase of the overall fluorescence due to the exchange of a mixture having $3 \mathrm{mg} \mathrm{mL}^{-1} \mathrm{P} 104$ micelles with $\mathrm{PyC}_{18}$ and liposomes suspension at the following concentrations: $6,8,10$ and $15 \mathrm{mg} \mathrm{mL}^{-1}$. The measurement temperature is $37^{\circ} \mathrm{C}$ at a $\mathrm{pH}=6.5$. (Solid line is only a guide to the eye). increases with increasing liposomes concentration. This means that this process is a second order kinetics, which is most likely due to a bimolecular phenomenon resulting from the cooperative interactions between $\mathrm{P} 104$ micelles bearing the $\mathrm{PyC}_{18}$ and liposomes. Since the overall intensity could also be influenced by some optical artifacts, an extra confirmation was obtained from the variation of the $\mathrm{PyC}_{18}$ lifetime throughout a kinetics experiment performed by using a homemade single photon counting spectrometer. A P104 solution containing small amounts of $\mathrm{PyC}_{18}$ was mixed with a liposomes suspension. The excimer of this solution was chosen to be small enough to be able to quantify the pyrene lifetime from the decay of the signal (Fig. 7a).

After mixing P104 micelles with $\mathrm{PyC}_{18}$ and liposomes, the lifetime $\left(\tau_{\mathrm{PyC}_{18}}\right)$ increases with time reaching a maximum around $80 \mathrm{~min}$ for liposomes suspension with a concentration of $15 \mathrm{mg} \mathrm{mL}^{-1}$ (Fig. 7b). The increase of $\tau_{\mathrm{PyC}_{18}}$ during the growth period of this kinetics is similar to the one observed using the $I_{\mathrm{EX}}$ and $I_{\mathrm{MON}}$ intensities. The kinetic constant $\left(k_{\text {lifetime }}\right)$ calculated from the maximum of the $\tau_{\mathrm{PyC}_{18}}$ is similar to that calculated also from $I_{\mathrm{EX}}$ and $I_{\mathrm{MON}}$ intensities. All of this confirms that
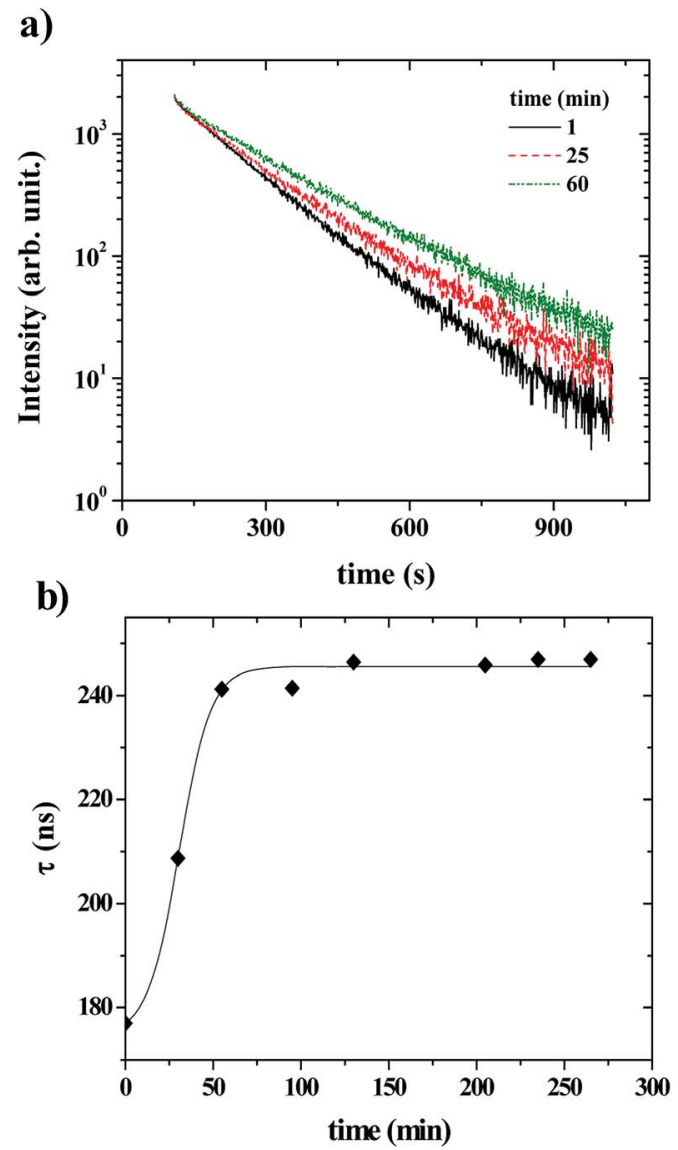

Fig. 7 (a) Kinetics experiment for a mixture of P104 solution (3 mg $\mathrm{mL}^{-1}$ ) containing small amounts of $\mathrm{PyC}_{18}$ with a liposomes suspension (15 mg mL ${ }^{-1}$ ) for different measurement times. The excimer of this solution was chosen to be small enough to be able to quantify the pyrene lifetime from the decay of the signal (a). (b) $\tau_{\mathrm{PyC}_{18}}$ as a function of time. The measurement temperature is $37^{\circ} \mathrm{C}$ at a pH $=6.5$. (Solid line is only a guide to the eye). 
the observed phenomenon is due to a slow change of the environment of the $\mathrm{PyC}_{18}$ within the $\mathrm{P} 104$ micelles, as proposed previously. One possible explanation for this slow change of the environment within the micelles is the slow migration of some of the additives of the liposomes that could reduce the oxygen solubility within the micelles. Therefore, the increase of the growth rates of $k_{\text {exchange }}\left(1 / \tau_{\max }\right)$ could mean that this phenomena results after a collision between P104 micelles bearing $\mathrm{PyC}_{18}$ with liposomes and the transfer of the additives from liposomes to P104 micelles during the collision. This process can be assimilated with an adhesion-collision process, in which exchange could occur.

However, during the growth process, the concentration of $\mathrm{PyC}_{18}$ within the micelles does not change significantly, otherwise one would observe a significant decrease of $I_{\mathrm{EX}}$ and a growth of $I_{\mathrm{MON}}$. Even if the monomer and the excimer intensities increase in the first part of the kinetics (Fig. 5a and b), their ratio $\left(I_{\mathrm{EX}} / I_{\mathrm{MON}}\right)$ contain the information about the fraction of micelles bearing more than two $\mathrm{PyC}_{18}$ molecules. For a low average number of pyrene micelles $\langle n\rangle<0.5, I_{\mathrm{EX}} / I_{\mathrm{MON}}$ can be considered proportional to $\langle n\rangle .^{48}$ The $I_{\mathrm{EX}} / I_{\mathrm{MON}}$ ratio is then used to estimate the kinetic constants of $\mathrm{PyC}_{18}$ migration from micelles to liposomes.

Fig. 8 shows $I_{\mathrm{EX}} / I_{\mathrm{MON}}$ decays as a function of time for a mixture of $3 \mathrm{mg} \mathrm{mL}{ }^{-1} \mathrm{P} 104$ micelles containing $\mathrm{PyC}_{18}$ with GUVs suspension at different concentrations. The observed peaks from the evolution of the monomer and the excimer intensities disappear in this representation. This ratio will then depend mainly on the average number of $\mathrm{PyC}_{18}$ per micelles, resulting in the best way to quantify the exchange dynamics between P104 micelles containing $\mathrm{PyC}_{18}$ and liposomes. From the time-scan analysis of $I_{\mathrm{EX}} / I_{\mathrm{MON}}$ it is possible to obtain the main relaxation time $\left(\tau_{\text {dynamics }}\right)$ of the global exchange dynamics between micelles and liposomes. The kinetic decays can be simulated by a mono-exponential function with an apparent relaxation time.

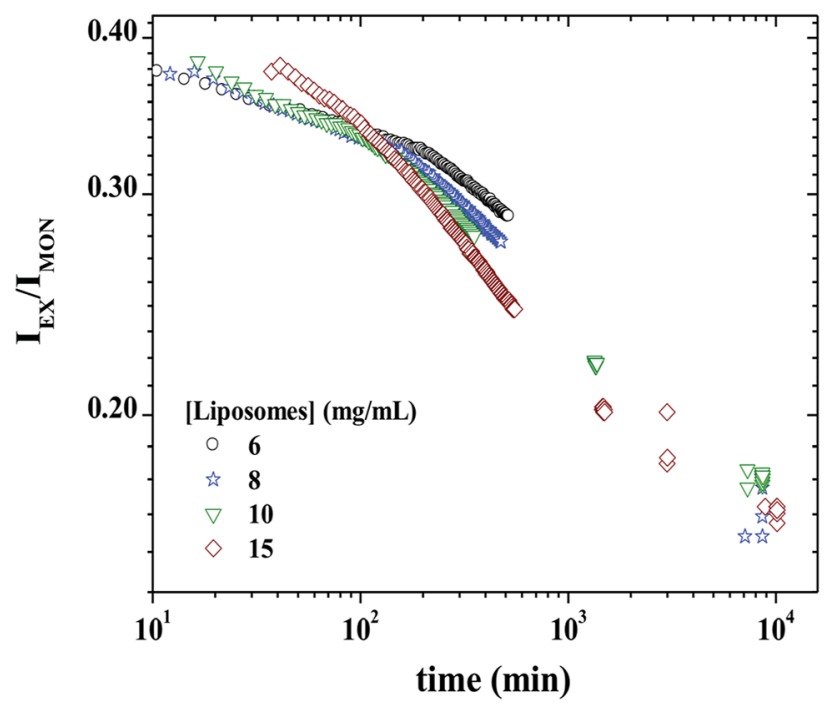

Fig. $8 I_{E X} / I_{M O N}$ decay as a function of time obtained during the exchange of $3 \mathrm{mg} \mathrm{mL}^{-1} \mathrm{P} 104$ micelles containing $\mathrm{PyC}_{18}$ with liposomes suspensions having the following concentrations: $6,8,10$ and $15 \mathrm{mg} \mathrm{mL}^{-1}$. The measurement temperature is $37^{\circ} \mathrm{C}$ at a $\mathrm{pH}=6.5$.
The kinetic constant, $k_{\text {dynamics, }}$ of P104 micelles-liposome exchange can be then quantified from the reciprocal of the apparent relaxation time obtained from the following expression:

$$
I_{\mathrm{EX}} / I_{\mathrm{MON}}=A e^{-t / \tau_{\mathrm{dynamics}}}+B
$$

where $A$ and $B$ are the constants obtained from the fit of the experimental results.

It is worth to mention that the apparent relaxation time ( $\left.\tau_{\text {dynamics }}\right)$ obtained from the mono-exponential function is similar to the average value $\langle\tau\rangle$ calculated from the fit to two exponentials. This was also valid for the case of the exchange dynamics at equilibrium in triblock copolymer micelles. ${ }^{48}$

\subsection{Liposomes concentration dependence on the $\mathrm{PyC}_{18}$ vectorization dynamics}

When the kinetics are repeated for different mixtures containing P104 micelles with a constant concentration and liposomes suspensions having different concentrations, a linear dependence of the exchange rate $k_{\text {dynamics }}=1 / \tau_{\text {dynamics }}$ with liposomes concentration is obtained. Fig. 9 shows the kinetic constant $\left(k_{\text {dynamics }}\right)$ dependence with the liposomes concentration in a mixture containing $\mathrm{P} 104$ micelles filled with $\mathrm{PyC}_{18}$ at a concentration of $3 \mathrm{mg} \mathrm{mL} \mathrm{m}^{-1}$. It is possible to observe an increment on $k_{\text {dynamics }}$ values with the increase of liposomes concentration in the mixture. The linear behavior obtained within the concentration range from 8 to $17.5 \mathrm{mg} \mathrm{mL}^{-1}$ is explained with the following equation:

$$
k_{\text {dynamics }}=k_{1}+k_{2} \text { [liposomes] }
$$

Firstly, a linear dependence of $k_{\text {dynamics }}$ as a function of the liposomes concentration with a kinetic constant called $k_{2}$, or fusion-adhesion kinetic constant, is considered as a second

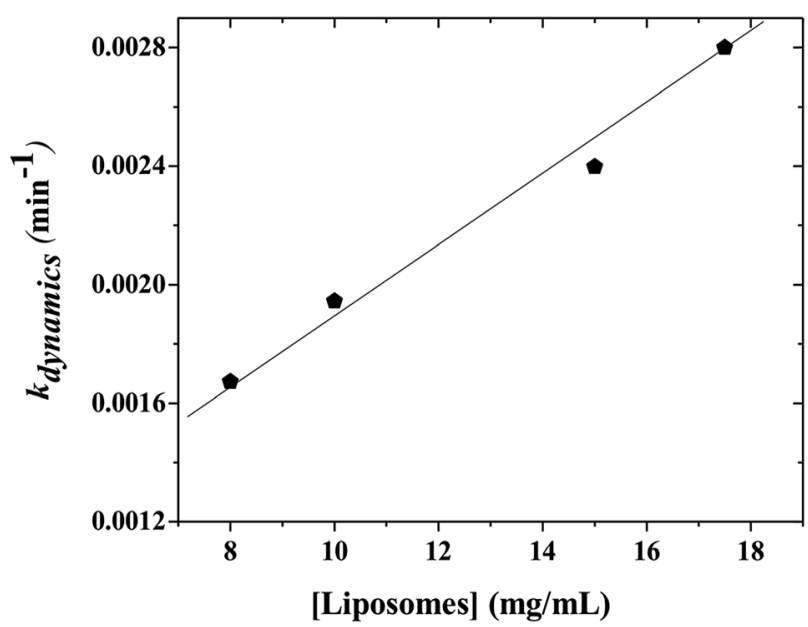

Fig. 9 Kinetic constant $\left(k_{\text {dynamics }}\right)$ calculated from the fits of the exchange decays obtained for the mixtures of P104 micelles containing $\mathrm{PyC}_{18}$ and liposomes suspension as a function of liposomes concentration. The measurement temperature is $37^{\circ} \mathrm{C}$ and the $\mathrm{pH}=$ 6.5 . 
order mechanism. Therefore, the exchange dynamics between P104 amphiphilic block copolymers and liposomes consists in a collective mechanism involving fusion-adhesion, exchange and separation. This second order mechanism depends on the variation of the amount of liposomes in the suspension.

The kinetic constants, $k_{\text {dynamics }}$, obtained from the exchange dynamics between P104 micelles (unpublished results) and those obtained from the exchange dynamics between P104 micelles and liposomes are compared in terms of their dependence with the number of empty micelles and the number of empty liposomes (Fig. 10a and b). The rate of collision-adhesion exchange, $k_{2}$, calculated from the slope of the $k_{\text {dynamics }}$ as a function of the molar concentration of liposomes is $k_{2}=1256$ $\mathrm{M}^{-1} \mathrm{~s}^{-1}$. This value is 50 times the fusion rate of P104 micellesmicelles, which is equal to $25 \mathrm{M}^{-1} \mathrm{~s}^{-1}$.

The exchange rate via collision-adhesion-exchange process is the product of a diffusion controlled rate $k_{\mathrm{diff}}$ and the probability of adhesion-exchange $\left(P_{\text {reac }}\right)($ eqn (3)).

$$
k_{2}=k_{\text {fus }}=k_{\text {diff }} P_{\text {reac }}
$$

The diffusion controlled rate $k_{\text {diff }}$ can be written as:

$$
k_{\text {diff }}=4 \pi N_{\mathrm{A}}\left(R_{\mathrm{h} 1}+R_{\mathrm{h} 2}\right)\left(D_{1}+D_{2}\right) \times 1000
$$

where $N_{\mathrm{A}}$ is the Avogadro number, $R_{\mathrm{h} 1}$ and $R_{\mathrm{h} 2}$ are the hydrodynamic radius of liposomes and P104 micelles, respectively. $D_{1}$ and $D_{2}$ are the diffusion coefficients of liposomes and the P104 micelles, respectively. Using the Stokes-Einstein eqn (5) it is possible to determine the diffusion-controlled coefficients for the micelle-micelle exchange and the liposome-micelles exchange.

$$
R_{\mathrm{h}}=k_{\mathrm{B}} T / 6 \pi \eta D
$$

where $k_{\mathrm{B}}$ is the Boltzmann constant, $T$ is the temperature and $\eta$ is the water viscosity.
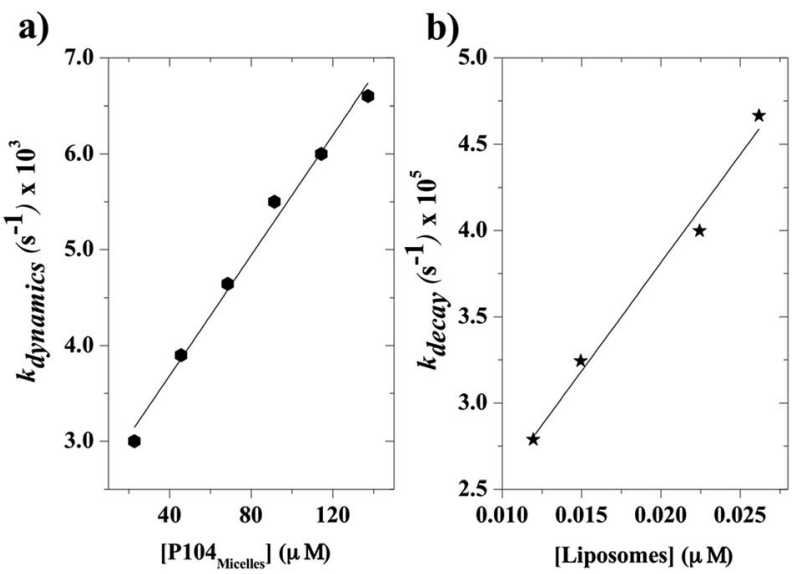

Fig. 10 (a) Kinetic constant $k_{\text {dynamics }}$ calculated from the fits of the exchange decays of $\mathrm{PyC}_{18}$ in $\mathrm{P} 104$ to the single exponential, plotted against the concentration of empty $\mathrm{P} 104$ micelle, (b) kinetic constant $k_{\text {dynamics }}$ calculated from the fits of the exchange decays of the mixtures of $\mathrm{P} 104$ micelles containing $\mathrm{PyC}_{18}$ and liposomes suspension, plotted against the concentration of empty liposomes. The measurement temperature is $37^{\circ} \mathrm{C}$ and the $\mathrm{pH}=6.5$.
For the liposome-micelles case, $k_{\text {diff }}=5 \times 10^{10} \mathrm{M}^{-1} \mathrm{~s}^{-1}$ while for micelle-micelle case $k_{\text {diff }}=7 \times 10^{9} \mathrm{M}^{-1} \mathrm{~s}^{-1}$. The collision rate of micelle-liposome is higher than that of micelle-micelles due to the liposome size. Therefore, the probability of adhesion-exchange $\left(P_{\text {reac }}\right)$ is $1.25 \times 10^{-8}$, which is in the same order of magnitude of P104 micelle-micelle $P_{\text {reac }}$ $\left(2.4 \times 10^{-8}\right)$. This suggests that P104 micelles control the adhesion-exchange process of P104-liposome system.

On the other hand, a first order mechanism with a rate independent of the liposomes concentration and with a kinetic constant called $k_{1}$ is related to the exit-entry process of the probe (dominated by water solubility, which is very low), to the exchangeassisted by the unimer (almost negligible) of the probe or to fission-fusion exchange. A moderately water soluble molecule as pyrene $\left(10^{-7} \mathrm{~mol} \mathrm{~L}^{-1}\right)$ can be mainly exchanged through an exitentry process having a rate one magnitude greater than the rate observed in this dynamic. In addition, the $\mathrm{C}_{18}$ chain present in the pyrene derivative, $\mathrm{PyC}_{18}$, reduces its solubility in water and causes the exit ratio to be negligible during the experiment. To confirm this statement, complementary experiments were performed, as the limitation for the exit-entry process of the $\mathrm{PyC}_{18}$ is the insolubility in water $\left(C_{\mathrm{w}}\right)$ or the diffusion through the core/corona of micelles. A dialysis tubing cellulose membrane (which is supposed to be permeable for free pyrene) with P104 micelles containing $\mathrm{PyC}_{18}$ was left in a GUVs suspension during one week. The emission spectra of this GUVs suspension showed a very low signal allowing concluding that exit-entry of $\mathrm{PyC}_{18}$ into GUVs suspension ( $25 \mathrm{mg} \mathrm{mL}^{-1}$ ) has to be experimentally discarded. Some results are also obtained for $\mathrm{PyC}_{18}$ in water. Then, the emission spectra of the liposomes suspensions in contact with the bag containing P104 micelles with $\mathrm{PyC}_{18}$ and water with $\mathrm{PyC}_{18}$ do not present any appearance of a specific fluorescent peak. It is then shown that the exchange of the $\mathrm{PyC}_{18}$ probe by exit-entry of the micelles to the liposomes is not crucial in the exchange dynamics between micelles and liposomes.

Furthermore, a variation on the chain-length of the pyrene derivative would affect the first order mechanism that presents a linear velocity rate independent of the liposomes. This first order process has been previously shown to be sensitive to the structure of the probe in Triton X-100 micelles. ${ }^{59}$ Various pyrene derivatives, i.e. 1-octylpyrene $\mathrm{PyC}_{8}$, 1-dodecylpyrene $\mathrm{PyC}_{12}$ and $\mathrm{PyC}_{18}$, were tested and caused an increase on the first-order process rate with the decrease of the size of the probe, directly related with the decrease on the hydrophobicity of the molecule. ${ }^{59,63}$ So one would also expect an interesting variation of, mainly, the first order mechanism as a function of pyrene derivative chain-length in our study system.

Finally, the results allow proposing an interaction mechanism between P104 triblock copolymer micelles and liposomes suspensions dominated by collective dynamics that could involve the following steps: collision of a micelle and a liposome, adhesion of micelles on the lipidic membrane, transfer of solute inside the lipidic membrane of the liposome followed by a possible separation (Fig. 11). The vectorization dynamics of hydrophobic drugs through vectors such as amphiphilic block copolymers can be followed, studied and quantified by using this fluorescence technique. 


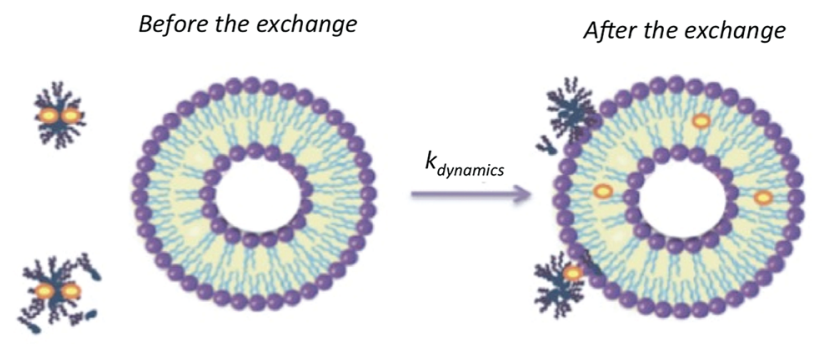

Fig. 11 Schematic representation of the exchange mechanism between $\mathrm{P} 104$ micelles containing a fluorescent probe $\left(\mathrm{PyC}_{18}\right)$ and liposomes.

\section{Conclusions}

P104 triblock copolymer micellization was firstly studied in water and in a liposomes suspension in order to determine P104 critical micellar concentration at $37^{\circ} \mathrm{C}$. The exchange dynamics between amphiphilic block copolymers and liposomes suspensions were successfully monitored by using a hydrophobic fluorescent probe that can be exchanged via different mechanisms. The evolution of the emission spectra as a function of time was treated in terms of the ratio given by the values obtained from the integration of the excimer intensity peak (440 nm $<I_{\mathrm{EX}}<550 \mathrm{~nm}$ ) and the integration of the monomer intensity peak (366 nm $<I_{\text {MON }}<425 \mathrm{~nm}$ ). It was found that the decrease of the ratio $I_{\mathrm{EX}} / I_{\mathrm{MON}}$ with time follows a singleexponential decay after mixing liposomes suspension with P104 micelles containing $\mathrm{PyC}_{18}$, from which it is possible to quantify the exchange time constant.

Finally, it was demonstrated that the exchange dynamics between amphiphilic block copolymer micelles and liposomes is a collective mechanism that follows a first order mechanism with linear velocity rate independent of the liposomes concentration and a second order mechanism with linear dependence of $k_{\text {dynamics }}$ as a function of the liposome concentration. It presumably involves the collision of a micelle and a liposome, the adhesion of micelles on the lipidic membrane and the transfer of solute inside this lipidic membrane followed by a possible separation.

\section{Conflicts of interest}

There are no conflicts to declare.

\section{Acknowledgements}

Dr J. F. A. Soltero acknowledges to CONACYT for financial support through project No. 223549. L. M. Bravo-Anaya acknowledges the scholarship granted by CONACYT, the Bourse Eiffel scholarship granted by French Government, financial support granted by G. Bravo-Galván and Dr Marguerite Rinaudo for helpful scientific discussions. We acknowledge Raoul Zana from Institut Charles Sadron for the single photon counting spectrometer donation. We acknowledge Dr Hélène Galliard for her valuable help with conducting the experiments and Mohamed Karrouch, Eric Faivre, Frédéric Hugenell and
Didier Bleses for their technical support. We acknowledge Ana Medeiros for her help with performing Confocal Microscopy observations. The Laboratoire Rhéologie et Procédés is part of the LabEx Tec 21 (Investissements d'Avenir - grant agreement no. ANR-11-LABX-0030) and of the PolyNat Carnot Institut (Investissements d'Avenir - grant agreement no. ANR-11-CARN030-01).

\section{Notes and references}

1 E. Soussan, S. Cassel, M. Blanzat and I. Rico-Lattes, Angew. Chem., Int. Ed., 2009, 48, 274-288.

2 Y. Liu, T.-S. Niu, L. Zhang and J.-S. Yang, Natural Science, 2010, 2, 41-48.

3 P. Ramos-Cabrer and F. Campos, Int. J. Nanomed., 2013, 8, 951-960.

4 R. Waehler, S. J. Russell and D. T. Curiel, Nat. Rev. Genet., 2007, 8, 573-587.

5 M. Morille, C. Passirani, A. Vonarbourg, A. Clavreul and J.-P. Benoit, Biomaterials, 2008, 29, 3477-3496.

6 S. Ganta, H. Devalapally, A. Shahiwala and M. Amiji, J. Controlled Release, 2008, 126, 187-204.

7 D. E. Owens and N. A. Peppas, Int. J. Pharm., 2006, 307, 93102.

8 H. Laroui, D. S. Wilson, G. Dalmasso, K. Salait, N. Murthy, S. V. Sitaraman and D. Merlin, Am. J. Physiol.: Gastrointest. Liver Physiol., 2011, 300(3), G371-G383.

9 M. Murillo, S. Espuelas, S. Prior, A. I. Vitas, M. J. Renedo, M. M. Goñi, J. M. Irache and C. Gamazo, Rev. Med. Univ. Navarra, 2001, 45, 19-34.

10 C. Capasso, M. Hirvinen and V. Cerullo, Biomedicines, 2013, 1, 3-16.

11 M. Malmsten, Surfactants and Polymers in Drug Delivery, Marcel Dekker, New York, 2002, vol. 122, pp. 10-49.

12 K. K. Jain Drug Delivery Systems-An Overview, Drug Delivery Systems, vol. 437 of the Series Methods in Molecular Biology, pp. 1-50, 2008.

13 C. M. Pitsillides, E. K. Joe, X. Wei, R. R. Anderson and C.-P. Lin, Biophys. J., 2003, 84, 4023-4032.

14 D. S. Kohane, Biotechnol. Bioeng., 2007, 96, 203-209.

15 M. Hamidi, M.-A. Shahbazi and K. Rostamizadeh, Macromol. Biosci., 2012, 12, 144-164.

16 L. He, L. Yang, Z. R. Zhang, T. Gong, L. Deng, Z. Gu and X. Sun, Nanotechnology, 2009, 20, 455102.

17 G. Gaucher, M.-H. Dufresne, V. P. Sant, N. Kang, D. Maysinger and J. C. Leroux, J. Controlled Release, 2005, 109, 169-188.

18 G. Pembouong, N. Morellet, T. Kral, M. Hof, D. Scherman, M.-F. Bureau and N. Mignet, J. Controlled Release, 2011, 151, 57-64.

19 C. Allen, D. Maysinger and A. Eisenberg, Colloids Surf., B, 1999, 16, 3-27.

20 K. Letchford and H. Burt, Eur. J. Pharm. Biopharm., 2007, 65, 259-269.

21 S. Sakuma, M. Hayashi and M. Akashi, Adv. Drug Delivery Rev., 2001, 47, 21-37. 
22 S. Geresh, G. Y. Gdalevsky, I. Gilboa, J. Voorspoels, J. P. Remon and J. Kost, J. Controlled Release, 2004, 94, 391-399.

23 S. V. Vinogradov, T. K. Bronich and A. V. Kabanov, Adv. Drug Delivery Rev., 2002, 54, 135-147.

24 J.-H. Ryu, R. T. Chacko, S. Jiwpanich, S. Bickerton, R. P. Babu and S. Thayumanavan, J. Am. Chem. Soc., 2010, 132(48), 17227-17235.

25 N. A. Peppas, Curr. Opin. Colloid Interface Sci., 1997, 2, 531537.

26 M. L. Adams, A. Lavasanifar and G. S. Kwo, J. Pharm. Sci., 2003, 92, 1343-1355.

27 S. Zamani and S. Khoee, Polymer, 2012, 53, 5723-5736.

28 K. Y. Oh, T. K. Bronich and A. V. Kabanov, J. Controlled Release, 2004, 94(2-3), 411-422.

29 X. Zhao and P. Liu, ACS Appl. Mater. Interfaces, 2015, 7(1), 166-174.

30 M. Morell and J. Puiggalí, Polymers, 2013, 5(1), 188-224.

31 A. V. Kabanov, E. V. Batrakova and V. Y. Alakhov, J. Controlled Release, 2002, 82(2-3), 189-212.

32 T.-I. Kim, H. J. Seo, J. S. Choi, H.-S. Jang, J. U. Baek, K. Kim and J.-S. Park, Biomacromolecules, 2004, 5(6), 2487-2492.

33 V. Kabanov, E. V. Batrakova and V. Y. Alakhov, Adv. Drug Delivery Rev., 2002, 54(5), 759-779.

34 A. Akbarzadeh, R. Rezaei-Sadabady, S. Davaran, S. W. Joo, N. Zarghami, Y. Hanifehpour, M. Samiei, M. Kouhi and K. Nejati-Koshki, Nanoscale Res. Lett., 2013, 8, 102.

35 D. Papahadjopoulos and H. K. Kimelberg, Prog. Surf. Sci., 1973, 4, 141-232.

36 T. Pereira de Souza, P. Stano and P. L. Luisi, ChemBioChem, 2009, 10, 1056-1063.

37 F. Szoka and D. Papahadjopoulus, Proc. Natl. Acad. Sci. U. S. A., 1978, 75, 4194-4198.

38 P. Walde, K. Cosentino, H. Engel and P. Stanod, ChemBioChem, 2010, 11(7), 848-865.

39 P. Couvreur, Ann. Pharm. Fr., 2001, 59(4), 232-238.

40 S. Laurent, D. Forge, M. Port, A. Roch, C. Robic, L. V. Elst and R. N. Muller, Chem. Rev., 2008, 108, 2064-2110.

41 A. Llevot and D. Astruc, Chem. Soc. Rev., 2012, 41, 242-257.

42 M. Mohs and J. M. Provenzale, Neuroimaging Clin. N. Am., 2010, 20, 283-292.
43 X. Huang and C. S. Brazel, J. Controlled Release, 2001, 73, 121-136.

44 D. Han, X. Tong and Y. Zhao, Macromolecules, 2011, 44(3), 437-439.

45 Z. Peg, H.-W. Chen, H. J. Paholak and Du-X. Sun, J. Tumor, 2013, 1(2), 7-15.

46 E. V. Batrakova and A. V. Kabanov, J. Controlled Release, 2008, 130(2), 98-106.

47 F. Meng, Z. Zhong and J. Feijen, Biomacromolecules, 2009, 10, 197-208.

48 Y. Rharbi, Macromolecules, 2012, 45, 9823-9826.

49 R. Koynova and M. Caffrey, Biochim. Biophys. Acta, 1998, 1376, 91-145.

50 E. Lessner, M. Teubner and M. Kahlweit, J. Phys. Chem., 1981, 85, 3167-3175.

51 G. Fritz, G. Scherf and O. Glatter, J. Phys. Chem., 2000, 104, 3463.

52 G. G. Warr and F. Grieser, J. Chem. Soc., Faraday Trans., 1986, 1, 1813-1828.

53 P. Alexandridis and T. A. Hatton, Colloids Surf., A, 1995, 96, 1-46.

54 T. Sakai and P. Alexandridis, Nanotechnology, 2005, 16, S344S353.

55 S. T. Crooke, Antisense Drug Technology: Principles, Strategies, and Applications, CRC Press, 2nd edn, 2007.

56 P. L. Luisi and P. Walde, Giant Vesicles in Perspective in Supramolecular Chemistry, John Wiley \& Sons, Chichester, U.K., 2000, vol. 6.

57 A. Petelska and Z. Figaszewski, Biophys. J., 2000, 78, 812-817.

58 F. Quemeneur, Relationship between mechanical parameters and behaviour under external stresses in lipid vesicles with modified membranes. Data analysis, statistics and probability, PhD thesis, Université de Grenoble, 2010.

59 Y. Rharbi, M. Li, M. A. Winnik and K. G. Hahn, J. Am. Chem. Soc., 2000, 122, 6242-6251.

60 Y. Rharbi, N. Bechthold, K. Landfester, A. Salzman and M. A. Winnik, Langmuir, 2003, 19, 10-17.

61 Y. Rharbi and M. A. Winnik, Langmuir, 1999, 15, 4697-4700.

62 Y. Rharbi, V. Kitaev and M. A. Winnik, Langmuir, 1999, 15, 2259-2266.

63 Y. Rharbi and M. A. Winnik, J. Phys. Chem. B, 2003, 107, 1491-1501. 